DOI: https://doi.org/10.47405/mjssh.v6i11.1120

\begin{tabular}{|c|c|}
\hline S & Malaysian Journal of Social Sciences and Humanities (MJSSH) \\
\hline Malaysian Journal of & Volume 6, Issue 11, November 2021 \\
\hline (MJ-sSH) & e-ISSN : 2504-8562 \\
\hline & $\begin{array}{l}\text { Journal home page: } \\
\text { www.msocialsciences.com }\end{array}$ \\
\hline
\end{tabular}

\title{
Selebriti dan Pemasaran Digital: Kepentingan Penglibatan Selebriti di Laman Media Sosial Instagram
}

\author{
Liyana Mohd Ramly¹, Mohd Azul Mohamed Salleh², Mohd Nur Shahizan Ali² \\ 1Pengajian Liberal, Fakulti Komunikasi dan Pengajian Media, Universiti Teknologi MARA, Malaysia \\ ${ }^{2}$ Pusat Kajian Media dan Komunikasi, Fakulti Sains Sosial dan Kemanusiaan, Universiti Kebangsaan Malaysia (UKM), \\ Malaysia \\ Correspondence: Liyana Mohd Ramly (liyana_ramly@uitm.edu.my)
}

\begin{abstract}
Abstrak
Penglibatan selebriti dalam penggunaan laman media sosial telah memberi banyak manfaat kepada selebriti pada zaman sekarang. Kajian ini meneliti keterlibatan selebriti dalam penggunaan platform media sosial untuk lebih memahami sebab-sebab tertentu penglibatan selebriti 24/7. Kajian itu juga mengenal pasti potensi dan hasil yang menyebabkan selebriti mempunyai hubungan dalam talian dengan pengikut. Informan bagi data kajian ini terdiri daripada 8 informan yang merupakan selebriti Malaysia ketika ini dengan pengikut melebihi lima ratus ribu pengikut di akaun Instagram mereka. Kajian ini telah dianalisis dan dipilih dengan menggunakan kaedah analisis tematik. Hasil kajian menunjukkan dengan jumlah pengikut yang ramai, selebriti telah secara aktifnya menceburi bidang pemasaran digital menggunakan Instagram bagi penjanaan pendapatan. Kajian ini juga menunjukkan bahawa kebarangkalian beberapa selebriti akan mempromosikan produk mereka, produk, jenama dan perkhidmatan orang lain dan akhirnya mendapat tajaan atau menjadi jurucakap jenama itu sendiri di Instagram. Kajian ini juga telah membuktikkan bahawa laman media sosial Instagram merupakan satu platform penting bagi pemasaran digital dan penjanaan pendapatan untuk selebriti. Implikasi praktikal penyelidikan ini menjelaskan hasil yang berkaitan dengan faktor-faktor penglibatan selebriti-pengikut di laman media sosial yang merangkumi pemahaman yang lebih baik tentang implikasi bagi pemasaran digital dalam kalangan selebriti di Malaysia.
\end{abstract}

Kata kunci: selebriti, penglibatan, pemasaran, pengurusan perniagaan, Instagram

\section{Celebrity and Marketing Online: The Importance of Celebrity Engagement on Instagram}

\begin{abstract}
The engagement of celebrities in the use of social media platforms have brought many advantages and benefaction to celebrities nowadays. This study examined the celebrity engagements in the use of social media platforms in better understanding the specific reasons of 24/7 celebrities involvements. The study also identified the potentials and the outcomes that led celebrities to have online relationships with their followers. The data of this study consists of 8 informants who are the current Malaysian celebrities with followers exceeding more than five hundred thousand followers on their Instagram accounts. The results of this study were analysed and selected using the thematic analysis methods. This study found that the celebrities who gained a large number of followers actively engaged with their Instagram followers for income generation. This study also showed that some
\end{abstract}


celebrities most likely will promote their products or other people's products, brands and services and end up getting sponsored or became the brand spokesperson themselves on Instagram. In addition, the results of the study also showed that Instagram is a convenient and cost-effective platform that significantly matters with regards to the notion of business management, advertising and marketing. The implications of this study are limited to only certain celebrities on social media platforms. Nevertheless, the practical implications and conclusion that can be drawn from this study are very much related to the degree and type of celebrity-followers engagements on social media which critical in having a better understandings towards social media influencers and the spectrum of creative marketing amongst celebrities in Malaysia.

Keywords: celebrity, engagement, marketing, business management, Instagram

\section{Pengenalan}

Jaringan sosial seperti laman media sosial merupakan satu langkah yang bijak untuk mengembangkan perniagaan atau mengembangkan jaringan hubungan sosial dengan membuat 'connection' melalui individu (Appel et al., 2020). Hal ini telah tular dan menjadi satu medium komunikasi yang popular untuk skala yang besar (Geser, 2010; Remanadhan, 2013). Jaringan sosial dalam talian merupakan inovasi baru yang mempunyai banyak cabaran yang boleh dikaji selidik kerana ia mempunyai lebih daripada satu bilion pengguna di seluruh dunia dan kebiasaannya, masyarakat mengakses jaringan sosial dalam talian dengan menggunakan komputer dan juga telefon pintar (Appel et al., 2020). Selebriti di Malaysia juga tidak ketinggalan menggunakan laman media sosial dalam kehidupan seharian mereka.

Turner (2010) dalam kajiannya mengatakan bahawa selebriti adalah orang yang mempunyai penglibatan dalam sukan, filem, muzik, atau bidang budaya. Dengan mengekspresikan diri dan memaparkan kekayaan melalui gambar, ia merupakan satu tarikan media visual yang mendapat banyak sokongan dan pengaruh daripada pengikut sekali gus memudahkan pemasaran produk dan wujudnya jenama dari selebriti (Marwick, 2013). Selebriti dikatakan mempunyai pengaruh di media massa kerana selebriti adalah individu yang terkenal (known for being known) (Fraser \& Brown, 2002). Selebriti umumnya dianggap mempunyai status sosial yang tinggi dalam komuniti dan disebabkan hal ini, selebriti perlu mempunyai akaun laman media sosial untuk mengekalkan pengikut (followers) dan kekal relevan di dalam industri (Soo, 2016).

Walau bagaimanapun, teknologi telah mengubah hubungan antara selebriti dan pengikut secara lebih cepat dan pantas. Peralihan dari program televisyen dan majalah yang berfokus kepada selebriti ke laman web selebriti dan profil laman media sosial membolehkan pengikut meneroka "engagement" dengan lebih mendalam mengenai selebriti. Engagement secara sederhana berarti tahap penglibatan komunikasi dua arah, yang menurut pakar komunikasi Wilbur Schramm (1954) adalah komunikasi interaksional. Dengan pertumbuhan laman media sosial seperti contoh Twitter, Instagram dan Facebook, maklumat mengenai selebriti lebih banyak dan mudah didapati. Laman media sosial telah mengubah kemampuan selebriti untuk menguruskan gambar mereka dalam talian dan berhubung terus dengan pengikut mereka (Schouten, Janssen \& Verspaget, 2020).

Dewasa ini, produk, jenama dan kempen sosial sering menggunakan selebriti untuk membantu proses periklanan kerana pengaruh selebriti yang kuat dalam kalangan masyarakat (Miller \& Allen, 2012; Fraser \& Brown, 2002). Selebriti kini dikonseptualisasikan sebagai jenama manusia, "human brand" (Thomson, 2006, hlm. 104). Sama seperti jenama lain, selebriti dengan berhati-hati menguruskan kelab dalam talian mereka yang dipromosikan kepada pengikut. Selebriti kini menggunakan teknologi laman media sosial dengan lebih terkawal dan teratur mengenai jenama peribadi mereka, dengan menghantar "kemas kini status", "suka" dan imej produk, bahkan bertindak balas terhadap komen yang diberikan oleh pengikut (Kowalczyk \& Pounders, 2016). Contoh laman media sosial yang popular dan sering digunakan oleh selebriti adalah Instagram.

Instagram merupakan laman media sosial yang mempunyai jumlah pengikut terbanyak di dunia pada 
tahun 2021 (Tankovska, 2021). Instagram adalah perkhidmatan laman media sosial perkongsian foto yang membolehkan pengguna mengambil gambar dan mengeditnya dengan filter (Linaschke, 2011). Linaschke (2011) turut menyatakan platform ini membolehkan pengguna menyiarkan dan berkongsi gambar mereka secara dalam talian dan terus dengan rakan dan pengikut mereka di laman media sosial yang lain. Pada Januari 2021, Instagram adalah salah satu laman media sosial yang paling popular di seluruh dunia, terutama di kalangan orang dewasa muda (Tankovska, 2021). Menurut data dari kajian Tankovska (2021) Instagram dilaporkan mempunyai satu bilion pengguna aktif bulanan pada bulan Jun 2018. Menurut beliau lagi, Instagram juga adalah platform untuk pengguna berkongsi gambar diri atau kandungan gambar lain seperti gambar perjalanan, dan mengikuti perkembangan atlet dan selebriti kegemaran (Tankovska, 2021).

Selain itu, Instagram telah melancarkan satu tetapan baru untuk membantu pemilik perniagaan berjaya di laman media sosial perkongsian foto tersebut (Instagram, 2021). Dengan strategi pemasaran yang tepat, pemilik perniagaan dapat mempromosikan produk dan perkhidmatan, memperkenalkan jenama mereka, dan meningkatkan penjualan di Instagram (Saige, Dec 22, 2020). Kebanyakan selebriti dan atlet menjadi jurucakap jenama dan menjana pendapatan sampingan dengan iklan di laman media sosial dan menyiarkan kandungan yang ditaja di akaun Instagram masing-masing (Christine et al., 2016; Gorin \& Dubied, 2018). Faktor yang menyebabkan selebriti mewujudkan akaun laman media sosial adalah untuk menarik perhatian peminat yang mudah terpesona dengan segala yang berkaitan dengan mereka serta dapat mencipta penglibatan secara terus dengan berinteraksi secara dua hala melalui laman media sosial (Clayton, 2013). Akaun laman media sosial selebriti diuruskan sama ada oleh pengurus selebriti, pengurus jenama, atau selebriti itu sendiri membuat usaha untuk berinteraksi dan melibatkan diri dengan peminat-peminatnya (Christine et al., 2016).

Kajian ini memberi tumpuan kepada selebriti yang menggunakan laman media sosial Instagram saluran sosial yang terkenal dengan kandungan berfokus pada foto. Tujuan kajian ini adalah untuk mengkaji dan melihat faktor penglibatan selebriti dalam penggunaan laman media sosial Instagram serta bagaimana tahap penglibatan selebriti dalam penggunaan laman media sosial Instagram.

\section{Sorotan Literatur}

Kadar penggunaan laman media sosial meningkat dengan ketara sejak beberapa tahun kebelakangan ini (Angulo, 2016). Laman media sosial yang memberi tumpuan kepada kandungan visual dan menggalakkan penyemakan imbas yang mudah (easy browsing) dan reaksi pantas seperti Instagram, Snapchat dan yang serupa telah menjadi popular (Chaffey, 2017). Selebriti berupaya menarik peningkatan jumlah pengikut di akaun laman media sosial mereka (Kapitan \& Silvera, 2016), dengan itu meningkatkan pengaruh mereka di laman media sosial. Pemasar juga menyedari potensi ini dan turut menggunakan selebriti untuk menyokong produk mereka (termasuk produk fizikal, perkhidmatan dan idea). Contohnya, nilai Selena Gomez lebih daripada 200 juta pengikut di Instagram, Facebook dan Twitter (Heine, 2016).

Kemunculan laman media sosial sememangnya memperluas pilihan pengguna untuk mengumpul maklumat produk dari pengguna lain dan memberi peluang kepada pengguna untuk menawarkan nasihat yang berkaitan dengan penggunaan mereka sendiri dengan melibatkan diri dari mulut ke mulut elektronik (eWOM)(Kozinets et al., 2010). Perbezaan eWOM dengan ciri-ciri komunikasi laman media sosial adalah seperti menghantar mesej kepada sesetengah individu dan mesej tersebut akan kekal untuk rujukan pengguna lain bagi jangka masa infinite (Zhang et al., 2010). Hasil penyelidikan terdahulu menunjukkan eWOM sebelum ini telah memberi lebih tumpuan dan fokus terhadap kebanyakan website komuniti dan forum yang membincangkan pendapat pengguna sahaja (Kozinets et al., 2010; Zhang et al., 2010). Walau bagaimanapun, terdapat kajian terbaru juga menyatakan menggunakan selebriti membolehkan jenama melalui penceritaan orang pertama (berbanding iklan biasa), yang dianggap lebih mesra dan lebih peribadi dan terbukti lebih berkesan dalam menarik pengguna (Chang et al., 2019).

Kozinets et al. (2010) menyatakan penggunaan taktik dan metrik baru pemasaran ini adalah disengajakan untuk mensasarkan dan mempengaruhi pengguna. Selebriti atau orang yang mempunyai 
pengaruh (opinion leaders) pemasaran sama ada dari mulut ke mulut, dalam talian atau di luar talian, adalah merupakan satu bentuk interaksi interpersonal (Zhang et al., 2010). Zhang et al. (2010) juga menyatakan selebriti masing-masing mempunyai asas pengikut tersendiri yang ramai dan komited kepada penyebaran idea yang dilakukan oleh selebriti melalui laman media sosial. Selebriti adalah orang yang mempunyai pengikut yang besar di laman media sosial Instagram. Kebiasaannya, pemilik perniagaan atau syarikat boleh membayar selebriti untuk memasarkan produk mereka kepada pengikutnya dengan cara alami (semula jadi). Hantaran tajaan ini biasanya halus dan tidak kelihatan seperti iklan dan amat berkesan kerana pengguna biasanya membenci iklan (Saraco Dec 18, 2020).

Pemilik Perniagaan atau syarikat telah menggunakan teknik pemasaran dengan memanfaatkan selebriti untuk mempromosikan produk atau juga dipanggil sebagai pengesahan selebriti (celebrity endorsement) (Freire et al., 2018). Selebriti boleh membuat pengesahan menggunakan sesuatu produk tersebut, sekaligus membuktikan bahawa mereka menyokong kandungan produk yang ditaja (Silva et al., 2015; Freire et al., 2018). Dalam kes laman media sosial Instagram terutamanya, tahap penglibatan (engagement rate) dapat dilihat sebagai satu pengukuran likeability (kesukaan) tertentu, kerana ia memperlihatkan jumlah like (suka) yang diberi oleh pengikut. Menurut kajian (Emma \& Matilde, 2017) terdapat keadaan di mana keinginan untuk membeli dan tahap penglibatan (engagement rate) timbul dalam kalangan pengikut apabila pemasaran sesuatu produk melibatkan pengesahan dari selebriti di laman media sosial Instagram.

Keupayaan dan kekuatan tahap penglibatan ini disedari oleh kebanyakan selebriti dewasa ini. Selebriti sedar akan kesan akaun media sosial mereka terhadap peminat dan hubungan (connections) yang mereka ciptakan (Emma \& Matilde, 2017). Oleh sebab itu, selebriti perlu mempunyai penglibatan yang tinggi (high engagement rate) dengan pengikutnya di laman media sosial (Kowalczyk \& Pounders, 2016). Salah satu contoh terbaik ialah: pemain bola sepak Cristiano Ronaldo manusia yang paling banyak diikuti di Instagram. Cristiano Ronaldo juga merupakan manusia pertama yang mencapai 200 juta pengikut di Instagram (The Top 20 Most Followed Instagram Accounts).

Oleh itu, untuk mengekalkan imej yang dinamik, selebriti perlu ada kadar penglibatan yang kerap dan tinggi di dalam laman media sosial Instagram dengan salah satu caranya membuat hantaran mengenai aktiviti mereka, informasi terkini dan sebagainya (Emma \& Matilde, 2017). Selebriti memerlukan pendedahan yang mencukupi untuk mengawal situasi yang menarik perhatian sebilangan besar pengguna laman media sosial (Wróblewski \& Grzesiak, 2020). Selebriti perlu menerima hakikat bahawa interaksi dengan pengguna laman media sosial boleh menjadi positif dan negatif, yang juga pada masa yang sama boleh memberi impak kepada produk jenama peribadi mereka atau produk orang lain (menjadi duta) dengan cara positif atau negatif (Kopera et al., 2014; Maric, 2020).

Berdasarkan satu kajian analisis kandungan oleh Ward (2016), beliau menyatakan tahap penglibatan selebriti di Instagram membawa kepada empat kategori interaksi kerjaya, peribadi, peminat, dan selebriti. Ward (2016) menyatakan hantaran (post) mengenai kerjaya melibatkan apa sahaja yang berkaitan dengan muzik, anugerah, penampilan promosi, dan sokongan produk. Kandungan peribadi termasuk suka, tidak suka, acara keluarga, dan acara / perjumpaan yang tidak akan diketahui oleh masyarakat umum. Hantaran untuk peminat adalah sesuatu yang ditujukan kepada peminat secara keseluruhan dan biasanya memasukkan "peminat" dalam caption, yang menunjukkan komunikasi dengan pengikut selebriti itu. Interaksi selebriti merangkumi kandungan di mana selebriti / media lain ditandai (tagged) sebagai pengakuan interaksi antara mereka (Ward, 2016).

\section{Metod Kajian}

\section{Pendekatan Kajian}

Kaedah kualitatif dipilih kerana ia memberi penjelasan dan maklumat deskriptif dapat dikumpulkan, oleh itu, kaedah kualitatif telah diguna pakai dengan mempertimbangkan tujuan dan metodologi penyelidikan kajian ini (Ford et al., 2018). Informan secara keseluruhan adalah 4 lelaki dan 4 wanita telah dipilih secara pensampelan bola salji. Informan yang dipilih merupakan selebriti berbangsa 
Melayu di Malaysia serta mempunyai ciri-ciri menggunakan laman media sosial Instagram dan mempunyai bilangan pengikut di Instagram seramai dari 258 ribu pengikut hingga 1.2 juta pengikut. Informan terdiri daripada umur 22 tahun hingga 37 tahun. Pekerjaan selebriti ini adalah penyanyi, pelakon, dan pengacara. Pada masa yang sama kesemua informan juga merupakan usahawan. Tahap pendidikan informan bermula dari peringkat SPM, Diploma, Ijazah Sarjana Muda hingga peringkat Ijazah Sarjana. Lokasi tempat tinggal semasa informan adalah di Selangor, Wilayah Persekutuan dan Johor Bahru. Informan kajian ini terdiri dari tiga informan berstatus berkahwin dan lima informan berstatus bujang.

\section{Data Demografi}

Bahagian ini akan membincangkan hasil kajian yang telah diperoleh daripada teknik analisis tematik terhadap maklum balas dari informan kajian ini. Berikut merupakan Jadual 1 yang menunjukkan data demografi informan bagi kajian ini;

Jadual 1: Data Demografi Informan Temu bual Secara Mendalam

\begin{tabular}{|c|c|c|c|c|c|c|c|}
\hline $\begin{array}{l}\text { No. } \\
\text { Bil }\end{array}$ & $\begin{array}{l}\text { No. } \\
\text { Siri }\end{array}$ & $\begin{array}{l}\text { Jantina/ } \\
\text { Bangsa }\end{array}$ & Umur & Status & $\begin{array}{l}\text { Tahap } \\
\text { Pendidikan }\end{array}$ & $\begin{array}{l}\text { Bilangan } \\
\text { Pengikut } \\
\text { Instagram }\end{array}$ & Pekerjaan \\
\hline 1. & L04 & $\begin{array}{l}\text { Lelaki / } \\
\text { Melayu }\end{array}$ & 28 & Bujang & Ijazah Sarjana & 1.1 juta & $\begin{array}{l}\text { Pelakon / } \\
\text { Pengacara/ } \\
\text { Usahawan }\end{array}$ \\
\hline 2. & L05 & $\begin{array}{l}\text { Lelaki / } \\
\text { Melayu }\end{array}$ & 37 & Bujang & Diploma & 866 ribu & $\begin{array}{l}\text { Pelakon / } \\
\text { Pengacara/ } \\
\text { Usahawan }\end{array}$ \\
\hline 3. & L06 & $\begin{array}{l}\text { Lelaki / } \\
\text { Melayu }\end{array}$ & 31 & Berkahwin & SPM & 800 ribu & $\begin{array}{l}\text { Penyanyi/ } \\
\text { Usahawan }\end{array}$ \\
\hline 4. & W07 & $\begin{array}{l}\text { Perempuan/ } \\
\text { Melayu }\end{array}$ & 22 & Bujang & SPM & 1 juta & Penyanyi \\
\hline 5. & L09 & $\begin{array}{l}\text { Lelaki / } \\
\text { Melayu }\end{array}$ & 37 & Berkahwin & SPM & 924 ribu & Penyanyi \\
\hline 6. & W10 & $\begin{array}{l}\text { Perempuan / } \\
\text { Melayu }\end{array}$ & 37 & Bujang & $\begin{array}{l}\text { Ijazah Sarjana } \\
\text { Muda }\end{array}$ & 1.2 juta & $\begin{array}{l}\text { Pelakon/ } \\
\text { Pengacara/ } \\
\text { Usahawan }\end{array}$ \\
\hline 7. & W11 & $\begin{array}{l}\text { Perempuan/ } \\
\text { Melayu }\end{array}$ & 31 & Berkahwin & Diploma & 258 ribu & $\begin{array}{l}\text { Pelakon/ } \\
\text { Pengacara/ } \\
\text { Usahawan }\end{array}$ \\
\hline 8. & W12 & $\begin{array}{l}\text { Perempuan/ } \\
\text { Melayu }\end{array}$ & 22 & Bujang & $\begin{array}{l}\text { Ijazah Sarjana } \\
\text { Muda }\end{array}$ & 446 ribu & $\begin{array}{l}\text { Penyanyi/ } \\
\text { Usahawan / } \\
\text { Pelajar }\end{array}$ \\
\hline
\end{tabular}

Jadual $1 \mathrm{di}$ atas menunjukkan informan terdiri daripada empat lelaki dan empat wanita dari pelbagai peringkat umur. Bilangan pengikut informan di Instagram bermula dari 258 ribu pengikut hingga ke 1.2 juta pengikut. Tahap pendidikan informan bermula dari SPM hinggalah ke Ijazah Sarjana. Status informan terdiri dari status bujang dan status telah berkahwin. Pekerjaan informan juga adalah pelbagai iaitu pekerjaan sebagai pelakon, penyanyi, pengacara dan usahawan.

\section{Hasil Kajian}


Kajian ini dianalisis secara tematik dan berdasarkan maklumat yang diberikan oleh informan dalam sesi temu bual secara mendalam, data yang dipilih adalah relevan bagi mengembangkan tema yang dapat mencapai tujuan kajian. Penggunaan analisis tematik bertujuan untuk mendapatkan beberapa data yang berbeza dari kajian sebelumnya (Braun, Clarke, Hayfield, \& Terry, 2019).

Jadual 2: Pola Penggunaan Laman Media Sosial Instagram dalam Kalangan Informan Kajian.

\begin{tabular}{lll}
\hline Aspek & $\begin{array}{l}\text { Bilangan } \\
\text { Informan }\end{array}$ & $\begin{array}{l}\text { Peratusan } \\
(\%)\end{array}$ \\
\hline $\begin{array}{l}\text { Kekerapan melayari laman media sosial Instagram } \\
1 \text { - } 2 \text { jam sehari }\end{array}$ & 1 & $12.5 \%$ \\
3 - 6 jam sehari & 4 & $50 \%$ \\
7 - 9 jam sehari & 1 & $12.5 \%$ \\
Lebih dari 10 jam & 1 & $12.5 \%$ \\
\hline
\end{tabular}

Berdasarkan dari Jadual 2, seramai empat informan (50\%) telah melayari laman media sosial Instagram selama 3-6 jam dalam sehari, seorang informan (12.5\%) melayari laman media sosial Instagram selama 1-2 jam sehari, seorang informan (12.5\%) melayari laman media sosial Instagram selama 7-9 jam sehari dan seorang informan melayari (12.5\%) Instagram selama lebih dari 10 jam sehari. Daripada data di atas dapat disimpulkan bahawa kekerapan selebriti melayari laman media sosial adalah tinggi dan dalam jangka masa yang lama. Jumlah ini bertentangan dengan laporan industri yang menganggarkan jumlah masa yang dihabiskan setiap hari di media sosial mendekati 120 minit (Mander, 2016).

Dalam penyelidikan ini, beberapa tema melalui analisis tematik telah ditemui, dipilih dan diambil dari maklum balas informan yang terlibat (Braun et al., 2019). Berikut merupakan faktor-faktor penglibatan selebriti dalam penggunaan laman media sosial Instagram. Semua maklum balas telah disusun menjadi empat tema seperti berikut:

i. Mengikut peredaran zaman

ii. Pengurusan perniagaan dan pemasaran yang lebih efisien

iii. Pengemaskinian informasi diri dan kerjaya untuk mendapatkan tahap penglibatan yang tinggi dengan pengikut

iv. Perkongsian / penyebaran maklumat yang tidak bertujuan untuk penjanaan pendapatan

Jadual 3: Tema dan Kategori

Tema Sub-Tema

1. Mengikut Peredaran Zaman

2. Pengurusan Perniagaan dan Pemasaran Yang Lebih Efisien

3. Pengemaskinian Informasi Diri dan Kerjaya untuk mendapatkan Tahap Penglibatan yang Tinggi dengan Pengikut
-Mengikut peredaran zaman

-promosi produk sendiri -promosi produk orang lain -maklum balas segera dari pelanggan. -penjanaan pendapatan

-maklumat tentang aktiviti harian -interaksi dengan pengikut (likes, komen dan sebagainya) -maklumat tentang kerjaya -penjanaan pendapatan 


\section{Perkongsian Maklumat yang tidak bertujuan \\ -perkongsian gambar peribadi (foto album) untuk Penjanaan Pendapatan \\ -perkongsian berita semasa \\ -perkongsian kandungan hiburan/inspirasi}

\section{Tema 1: Mengikut Peredaran Zaman}

Hasil kutipan data mendapati kesemua empat dari lapan informan $(50 \%)$ menyatakan bahawa tujuan mereka membuka laman media sosial Instagram pada mulanya adalah kerana mengikuti peredaran zaman (trend) ketika itu. Informan menyatakan mereka pada ketika itu tidak langsung pernah terfikir bahawasanya laman media sosial ini akan memberi banyak manfaat kepada kerjaya mereka sebagai seorang selebriti. Informan wanita yang menepati tema 1 terdiri daripada dua orang iaitu W10 dan W11, manakala, informan lelaki pula terdiri dari dua informan iaitu L06 dan L05. Hal ini dibuktikan dengan dialog-dialog berikut:

\section{Jadual 4: Mengikut Peredaran Zaman (Wanita)}

\begin{tabular}{|c|c|}
\hline Tema 1 & Informan Wanita \\
\hline $\begin{array}{l}\text { Mengikut Peredaran } \\
\text { Zaman } \\
\text { Mengikut Peredaran } \\
\text { Zaman }\end{array}$ & $\begin{array}{l}\text { "Saya buka Instagram dulu sebab masa tu semua orang buka Instagram. Saya } \\
\text { buka Instagram kerana mengikuti perkembangan semasa" - Informan W10 } \\
\text { "Mengikut peredaran zaman, first, we have another platform that....other } \\
\text { than Facebook...so macam pada I, the best part is adalah Instagram pada } \\
\text { masa itu upload gambar sahaja"- Informan W11 }\end{array}$ \\
\hline & Jadual 5: Mengikut Peredaran Zaman (Lelaki) \\
\hline Tema 1 & Informan Lelaki \\
\hline $\begin{array}{l}\text { Mengikut Peredaran } \\
\text { Zaman } \\
\text { Mengikut Peredaran } \\
\text { Zaman }\end{array}$ & $\begin{array}{l}\text { "Okay, saya buka Instagram sebab masa tu tengah trending. Sebelum ni kan } \\
\text { ada Friendster.. saya buat, saya buat My Space, saya buat Facebook. Lepas tu } \\
\text { muncul Instagram benda baru. Saya suka benda baru. And then I download } \\
\text { Instagram. Masa tu saya pun dah jadi artis dah pun. So sesaja je." Informan } \\
\text { L05 }\end{array}$ \\
\hline
\end{tabular}

\section{Tema 2: Pengurusan Perniagaan dan Pemasaran Yang Lebih Efisien}

Kebanyakan informan menggunakan laman media sosial Instagram sebagai medium untuk menguruskan perniagaan mereka dan medium pemasaran dengan mudah dan lebih efisien kerana kandungan yang dihasilkan pengguna/selebriti dan pasaran untuk penglibatan dalam komuniti jenama media sosial mempunyai kesan positif terhadap perbelanjaan pembelian (Goh et al. 2013). Terdapat lima informan mempromosikan produk orang lain (L09, W10, W11, W07, W12) manakala seramai enam informan lagi mempromosikan produk sendiri (W10, W12, W11, L04 L06, L05). Terdapat dua definisi mengenai produk sendiri di sini iaitu 1) adalah bakat selebriti tersebut 2) produk yang dihasilkan/ dikeluarkan yang tiada kaitan dengan bakat selebriti tersebut seperti kopi sambal dan sebagainya. Aktiviti ini adalah penting bagi selebriti kerana ia merupakan salah satu cara selebriti menjana pendapatan sampingan selain dari menerima tawaran berlakon, menyanyi dan sebagainya.

Dapatan ini turut disokong oleh hasil kajian oleh Siti Aisya dan Aini Maznina (2019) yang menyatakan selebriti menggunakan platform laman media sosial mereka untuk mempromosikan produk sendiri atau produk orang lain kerana mereka dilantik sebagai duta produk atau berusaha menceburkan diri dalam 
bidang keusahawanan. Seorang informan (L05) berpendapat bahawa penggunaan Instagram membantu beliau untuk mendapatkan maklum balas (feedback) mengenai aktiviti atau perniagaan beliau dengan kadar segera berbanding zaman dahulu di mana selebriti terpaksa menggunakan wartawan dan surat khabar bagi mendapatkan sebarang maklum balas dan proses tersebut mengambil masa yang agak lama. Bukti-bukti dialog mengenai pengurusan perniagaan dan pemasaran produk lebih efisien menggunakan laman media sosial Instagram adalah seperti berikut:

Jadual 6: Pengurusan Perniagaan yang Lebih Efisien (Wanita)

\begin{tabular}{ll}
\hline Tema 2 & Informan Wanita \\
\hline & "Saya menggunakan Instagram untuk mempromosikan produk saya seperti \\
& brownies, produk pakaian dan juga ada menjadi duta produk dan telah \\
& menggunakan Instagram saya untuk mempromosikan produk tersebut.." - \\
& Informan W10 \\
Pengurusan & "Tujuan buka Instagram pada 2010... saya untuk mempamerkan, untuk \\
Perniagaan yang & advertise saya punya produk sendiri which is my talent lah..Saya juga ada \\
& mempromosikan produk orang lain dengan menjadi duta kepada produk \\
& tersebut" -Informan W12 \\
& "Kalau macam sekarang saya sudah ada produk sendiri iaitu produk \\
& berasaskan makanan. Saya juga menjadi duta produk orang lain...so kita \\
& akan selitkan sekali produk-produk yang kita bawa... saya ada menjadi duta \\
& untuk beberapa produk.." -Informan W11 \\
& "Saya buat masa ini tiada produk sendiri tapi saya dah mempromosikan \\
& produk lain sebab saya telah di lantik menjadi duta produk tersebut. Jadi saya \\
& kena buat posting... so thats the real attention.... untuk jemput orang ramai \\
& sebab saya macam public figure and when there's an event... I kena war-war \\
& kan benda tu lah... atau bila ada launching new product ....yang macam itu, \\
& so that people notice it through public figure.." -Informan W07 \\
\hline
\end{tabular}

Jadual 7: Pengurusan Perniagaan yang Lebih Efisien (Lelaki)

Tema $2 \quad$ Informan Lelaki

"Orang bagi saya barang/produk, saya teliti terlebih dahulu barang/produk apa. Kalau ia bersesuaian dan berkaitan dengan saya untuk saya share, saya rasa elok saya share. Macam contoh sekarang ni saya tengah nak simpan misai, ada orang bagi saya produk misai. Jadi, produk misai tu, saya share la apa kebaikan dan manfaat terhadap saya, beri informasi kepada siapa yang ingin simpan misai macam saya." - Informan L09

"Ya, saya mempromosikan produk diri saya iaitu lagu-lagu saya, that is my product nyanyian saya, karya saya itu adalah produk-produk yang saya jual.

Pengurusan Perniagaan yang lebih Efisien So itulah cara yang saya gunakan. Instagram merupakan medium yang terbaik yang pernah saya gunakan." Informan L06

"Instagram adalah salah satu platform untuk business, saya berinteraksi dengan pembeli-pembeli... saya boleh direct terus. Sebab sebelum ni kan, story update melalui paper, malay magazine kan, so sekarang media cetak bagi saya dah hancur, dah tak ada dah. So fans lebih suka online. So direct terus. Artis update gambar, shooting kat mana, drama apa, fans dah boleh tahu terus dah. On the spot. Kalau dulu kan sebulan, setengah bulan baru tahu keluar magazine semua kan.." Informan L05 
"Ada produk sendiri ada dululah tapi saya jarang buat produk sendiri sebab saya tak nak macam sekadar melepas batuk di tangga saja. Saya nak kualiti produk tu bagus supaya orang beli sebab kualiti bukan sebab saya, kadang saya akan keluarkan lah produk saya ikut musim. Produk orang lain jarang saya tak ambil sangat produk review". -Informan L04

\section{Tema 3: Pengemaskinian Informasi Diri dan Kerjaya untuk Meraih Tahap Penglibatan yang Tinggi dengan Pengikut}

Seterusnya, hasil kajian juga mendapati sebanyak enam informan (W10, W12, W07, L04, L06, L09) menyatakan mereka menggunakan Instagram untuk mengemas kini informasi tentang diri dan informasi mengenai kerjaya mereka untuk meraih tahap penglibatan yang tinggi dengan pengikut sekali gus menjana pendapatan. Pengemaskinian informasi diri dan kerjaya ini merujuk kepada selebriti yang menggunakan laman media sosial untuk mewar-warkan informasi berkaitan dengan bidang kerjaya yang merangkumi hiburan, isu-isu politik semasa atau isu-isu sukan. Hal ini telah dibuktikan oleh 6 orang informan yang menyatakan bahawa pentingnya selebriti mendapatkan penglibatan dari pengikut yang "mengikuti" atau "menyukai" mereka di laman media sosial yang berkaitan dengan kerjaya mereka kerana ianya menunjukkan wujudnya penglibatan komunikasi dua hala di antara selebriti dan peminat.

Di Instagram, jika selebriti hanya membuat siaran secara berkala dengan hashtag belum memberi jaminan bahawa kandungan tersebut akan kerap dan selalu menjangkau khalayak yang ingin disasarkan. Ini kerana, algoritma Instagram menentukan susunan hantaran yang dilihat (viewed) pengguna ketika melayari feeds Instagram dan selebriti perlu tahu bagaimana untuk mengemas kini algoritma Instagram ini untuk meningkatkan pendekatan dan penglibatan terhadap hantaran yang dilakukan bagi melaksanakan pemasaran di Instagram (Saraco, Dec 18, 2020). Empat informan (W12, W07, L04, L09) pula menyatakan mereka menggunakan laman media sosial Instagram sebagai platform untuk menarik perhatian peminat yang mudah terpesona dengan segala yang berkaitan dengan mereka agar wujudnya interaksi secara dua hala (penglibatan) dengan pengikut mereka bagi tujuan mendapatkan kerja/projek (job) untuk menjana pendapatan mereka. Ini kerana kebanyakan syarikat yang ingin memasarkan produk akan melihat tahap penglibatan dan interaksi di antara selebriti dengan pengikut-pengikutnya.

Tahap penglibatan diukur dengan membahagikan dapatan likes (suka) di foto dengan jumlah pengikut (Emma \& Matilde 2017). Selebriti juga dapat membalas interaksi dimulakan oleh peminat mereka dengan menggunakan pelbagai ciri Instagram, seperti membalas komen, menyukai foto / komen mereka, menandakannya dalam foto, atau bahkan menyiarkan semula siaran oleh peminat mereka (Siti Aisya \& Aini Maznina, 2019). Ini dibuktikan dengan dialog-dialog dari informan-informan seperti berikut;

Jadual 8: Pengemaskinian Informasi Diri dan Kerjaya untuk Meraih Tahap Penglibatan yang Tinggi dengan Pengikut (Wanita)

Tema 3

Wanita

"Sekarang ni mostly untuk buat promote apa yang terbaru tentang diri saya mostly apa yang tengah saya kerjakan dalam lapanganlah. Contohnya saya nak bagitahu saya punya follower apa yang saya tengah buat sekarang ni, maksudnya shooting atau ada program baru" -Informan W10

Interaksi Kerjaya untuk Penjanaan Pendapatan
"Saya akan post lagu cover, saya update event, lokasi keberadaan saya, untuk advertise my talent.. Ada peminat yang nak tahu saya pergi mana, buat apa... Update terbaru, sebab itu senang sebenarnya menggunakan Instagram ni.." -Informan W12 
"Saya gunakan Instagram basically untuk bekerja. Instagram ni kiranya bekerja sekali dengan life saya juga. Sebahagian dari kerja saya menggunakan Instagram. Penggunaan Instagram bagi saya $80 \%$ adalah untuk 'bekerja' sebab kalau saya pergi event saya perlu buat posting as a public figure or as a penyanyi. Jadi Instagram merupakan medium untuk menjana pendapatan bagi saya." -Informan W07

Jadual 9: Pengemaskinian Informasi Diri dan Kerjaya untuk Meraih Tahap Penglibatan yang Tinggi dengan Pengikut (Lelaki)

\begin{tabular}{ll}
\hline Tema 3 & Lelaki \\
& "Sebenarnya sekarang bila bekerja dalam bidang ni, saya kena aktif sebab \\
& stesen tv tengok follower, client tengok follower dan interaction tu penting \\
& untuk orang masuk brand (duta jenama) pada kita walaupun follower saya \\
& tinggi tapi interaction tak tinggi...dia tak kira. Akaun Instagram saya jenis \\
& akaun professional bukan akaun personal. Jadi jenis akaun professional ni \\
& saya boleh tahu audience saya punya demografik data. So peak hour saya \\
& boleh tahu. Saya boleh pos (hantar), saya boleh boost nak promote drama \\
Interaksi Kerjaya & dan lain-lain, jadi lebih detaillah. So kalau saya tak ada Instagram, audience \\
untuk Penjanaan & tak akan interact dengan selebriti yang baru macam saya ni, susah untuk \\
Pendapatan & orang nak tahu apa saya buat." - Informan L04 \\
& Maklumat...macam contohnya kalau saya ada mengeluarkan single \\
& terbaru...untuk memberitahu peminat peminat saya ....so daripada sana, \\
& saya akan update....so itulah cara ...cara termudah. -Informan L06 \\
& "Saya buka Instagram untuk saya kongsikan perkembangan saya kepada \\
& peminat disamping itu saya mempromosi diri. Saya beritahu apa yang saya \\
& buat sebab sesetengah peminat mungkin nak tahu, atau ada dah tahu apa \\
& kerja saya. Atau mungkin diorang nak tahu personal saya yang saya buat \\
& selain daripada menyanyi tu so Instagram merupakan medium yang paling \\
& sesuai." -Informan L09
\end{tabular}

\section{Tema 4: Perkongsian Maklumat Yang Bukan Untuk Penjanaan Pendapatan}

Tiga informan (W07, W10, L09) menggunakan laman media sosial Instagram untuk tujuan memuat naik gambar peribadi sebagai foto album dan memuat naik aktiviti harian agar dapat dijadikan contoh untuk tatapan pengikut. Empat informan (W07, W10, W11, L05) menyatakan mereka menggunakan laman media sosial Instagram untuk berkongsi maklumat yang mempunyai kandungan berunsurkan hiburan dan inspirasi dan yang bertujuan untuk memberikan sedikit sokongan moral kepada pengikut. Kesemua hantaran berunsurkan hiburan dan motivasi ini bukanlah bertujuan untuk menjana pendapatan tetapi adalah sebahagian daripada amal kebaikan (public awareness) yang ingin disebarkan.

Terdapat juga informan yang memuat naik hantaran (postings) dengan tujuan untuk menghilangkan tekanan dalam kalangan pengikutnya (L05).Selebriti sedar peranan mereka sebagai orang yang berpengaruh dan sering turut sama memuat naik hantaran-hantaran (postings) yang berunsurkan kempen kesedaran (advocates) dan sebagainya. Brockington dan Henson (2015) berpendapat bahawa advokasi selebriti telah menjadi penting sebahagian daripada cara di mana badan bukan kerajaan (NGO) yang berorientasikan pembangunan, dan amal amnya, berusaha untuk mencapai perubahan sosial dan politik. Dialog masing-masing adalah seperti berikut: 
Jadual 10: Perkongsian Maklumat Yang Bukan Untuk Penjanaan Pendapatan (Wanita)

\begin{tabular}{|c|c|}
\hline Tema 4 & Wanita \\
\hline $\begin{array}{l}\text { Perkongsian } \\
\text { Maklumat Yang } \\
\text { Bukan Untuk } \\
\text { Penjanaan } \\
\text { Pendapatan }\end{array}$ & $\begin{array}{l}\text { "Kalau ada moment yang saya suka, saya akan ambil gambar supaya saya } \\
\text { boleh post (hantar) supaya gambar itu kekal dekat Internet. So nanti kita } \\
\text { boleh rujuk balik dan tak ada lah hilang dekat telefon bimbit.. Saya juga } \\
\text { akan kongsikan aktiviti harian saya macam outfit of the day. Foto saya pergi } \\
\text { travel ke.. Kalau based on kerja, if I akan perform untuk "Drama Festival } \\
\text { Kuala Lumpur" and I akan dapat one poster untuk inform kepada peminat } \\
\text { yang saya akan perform di DFKL supaya tontonan dan sambutan tu ramai } \\
\text { dari peminat saya. Sometimes saya akan post macam misi "Dapur Kasih } \\
\text { Buat Syria". Jadi saya kongsikan di Instagram saya for public awareness } \\
\text { and advocates".- Informan W07 } \\
\text { "Apa yang saya kongsikan mostly about work and then ermm family er. } \\
\text { Kalau dulu mostly about family lah. Sekarang ni sebab kita dah kerja dalam } \\
\text { industri ni. Jadi operkongsian tu lenig kepada pasal pekerjaan dan saya suka } \\
\text { letak benda-benda yang memberi inspirasi kepada orang dekat luar sana."- } \\
\text { Informan W10 } \\
\text { "I pernah juga buat entertaining video apa semua itu untuk I kongsikan di } \\
\text { Instagram... and then, bila kita start ada followers.... So benda itu maintain } \\
\text { lah" -Informan W11 }\end{array}$ \\
\hline \multicolumn{2}{|r|}{ Jadual 11: Berkongsi Maklumat (Lelaki) } \\
\hline Tema 4 & Lelaki \\
\hline $\begin{array}{l}\text { Perkongsian } \\
\text { Maklumat Yang } \\
\text { Bukan Untuk } \\
\text { Penjanaan } \\
\text { Pendapatan }\end{array}$ & $\begin{array}{l}\text { Saya share gambar apa yang saya buat harini. Lepastu saya banyak share } \\
\text { benda-benda kerja sahaja. Sekarang ni baru sikit-sikit kita share yang patut } \\
\text { dengan isteri saya. Haaa itu-itu jela. Tu pon saya tak share all the way. } \\
\text { Sikit-sikit sahaja. Yang penting saya share." -Informan L09 } \\
\\
\text { "Saya share perkara-perkara yang boleh membantu menghilangkan stress. } \\
\text { Maksudnya benda tu lawak, kandungan yang berunsurkan joke untuk } \\
\text { tontonan pengikut saya, peminat-peminat saya dan sesiapa sahaja yang } \\
\text { melewati akaun Instagram saya." - Informan L05 }\end{array}$ \\
\hline
\end{tabular}

\section{Limitasi Kajian}

Meneroka penilaian penglibatan selebriti terhadap penggunaan laman media sosial mempunyai beberapa batasan tetapi memberi banyak peluang untuk penyelidikan dan penemuan. Terdapat banyak penyelidikan masa depan yang menarik untuk dipertimbangkan ketika memikirkan penglibatan selebriti di laman media sosial. Pertama, sampel ini mempunyai usia dalam lingkungan yang berbeza-beza dan bukan dalam lingkungan usia yang sama, sampel juga merupakan selebriti yang berlakon dan menyanyi dan terdiri alam kalangan selebriti berbangsa Melayu sahaja makanya kajian akan datang boleh membandingkan di antara selebriti bukan berbangsa Melayu di Malaysia. Memperluas kajian ini ke kumpulan bangsa yang lebih pelbagai akan memperkukuhkan sumbangan dalam penyelidikan jenama. Penyelidikan masa depan dapat menguji selebriti yang mempunyai pengaruh yang kuat di laman media sosial seperti mempunyai jumlah pengikut 5 juta dan ke atas. Mengkaji pelbagai jenis selebriti, termasuk juga ahli politik, usahawan terkenal dan mengkaji beberapa laman media sosial yang lain termasuk Facebook, Twitter dan Tik Tok. 


\section{Kesimpulan}

Laman media sosial telah mengubah hubungan antara selebriti dan pengikutnya. Selebriti dengan mudahnya dapat menyebarkan maklumat manakala pengikut zaman sekarang dengan mudahnya mendapatkan maklumat. Pada masa lalu, maklumat yang berkaitan dengan selebriti dibuat oleh ejen akhbar dan pakar perhubungan awam dan disampaikan kepada pengikut melalui media tradisional seperti radio, televisyen, majalah dan surat khabar (Kerrigan et al., 2011). Inovasi dalam teknologi terutamanya laman media sosial Instagram telah membolehkan selebriti mempunyai hak mutlak ke atas gambar mereka dan juga membolehkan pengikut berinteraksi secara langsung dengan selebriti (Dwivedi et al., 2021).

Secara keseluruhannya, media massa dan media sosial merupakan alat telekomunikasi yang penting pada era kini. Semenjak pandemik Covid-19 melanda dunia, rata-rata selebriti di Malaysia telah beralih ke penggunaan laman media sosial Instagram untuk penjanaan pendapatan. Ini kerana banyak acara hiburan atau seni membabitkan jumlah kehadiran yang ramai terpaksa dibatalkan. Contohnya konsert, penggambaran drama atau filem, acara anugerah, pelancaran filem dan sebagainya adalah dilarang sehingga ke jangka masa yang tidak diketahui sekali gus melumpuhkan pendapatan selebriti.

Disebabkan hal ini golongan selebriti telah mempelajari dan memanfaatkan cara terbaik untuk menyesuaikan diri dengan normal baharu dan dalam masa yang sama dapat menjana pendapatan. Antaranya memanfaatkan aplikasi teknologi dalam kerja sebagaimana yang dilakukan ramai dari rumah kini. Adaptasi ini membantu selebriti untuk terus berhubung (connections) serta 'menjual' jenama untuk meraih sumber pendapatan. Hasil kajian menunjukkan selebriti tidak lagi bergantung dengan wartawan dan media massa tradisional untuk menaikkan populariti mereka semata-mata. Selebriti dewasa ini, berupaya mempromosikan diri (termasuk bakat dan aktiviti harian), mempromosikan produk (sama ada produk sendiri ataupun produk orang lain) dengan hanya bergantung dengan penggunaan laman media sosial Instagram sahaja.

Laman media Instagram digunakan oleh selebriti kerana ianya merupakan satu aplikasi yang memudahkan penggunanya untuk menguruskan perniagaan terutamanya untuk membuat proses pemasaran yang menjimatkan kos dan masa. Pengiklan dan syarikat boleh belajar dari selebriti yang mempunyai pengikut yang ramai serta penglibatan yang tinggi di laman media sosial mereka. Selebriti melalui laman media sosial boleh menjana pendapatan sendiri dengan memuat naik hantaran promosi kerjaya atau produk jenama mereka sendiri (Vara, 2013). Terdapat kajian yang menyatakan bahawa produk jenama selebriti ini boleh mempengaruhi kredibiliti selebriti (Jin \& Phua, 2014).

Dalam perkembangan yang sama, hasil kajian ini mendapati selebriti juga menggunakan akaun laman media sosial Instagram sebagai platform untuk menyebarkan berita serta informasi tentang amal kebajikan yang dilakukan sendiri atau dilakukan oleh orang lain. Kesan dari hal ini terdapat beberapa kebaikannya seperti ramai peminat, pengikut atau pengguna dapat meneladani sifat baik yang ditunjukkan. Selebriti juga mendekati peminat untuk mendapatkan sokongan, untuk membuat pengumuman mengenai projek-projek terbaru, dan menyebarkan maklumat terkini agar wujudnya penglibatan di antara selebriti dan masyarakat. Hal ini diakui kerana selebriti mempunyai jutaan peminat dimana ianya mempercepatkan proses penyebaran berita. Selebriti juga turut sama membantu pengikutpengikut mereka yang merasa tertekan dengan memuat naik hantaran pada 1 Instagram yang boleh membantu menghilangkan tekanan seperti hantaran yang mempunyai unsur lucu, hiburan dan sebagainya. Ini menunjukkan selebriti turut menghulurkan bantuan dalam pelbagai bentuk mengikut kemampuan masing-masing.

Kesimpulannya, fenomena penglibatan selebriti di laman media sosial telah mewujudkan teknik pemasaran baru yang berkesan bagi mempromosikan produk di akaun laman media sosial di Instagram selebriti. Ini kerana laman media sosial selebriti berupaya mencapai capaian jumlah tontonan dalam skala yang besar dalam kalangan pengikutnya sendiri atau dalam kalangan penonton umum. Selain itu, tahap penglibatan selebriti di laman media sosial perlu kekal aktif agar sentiasa dilihat kekal relevan dan popular oleh pengikut, pemilik perniagaan, produksi filem dan sebagainya. Oleh hal yang demikian, penglibatan selebriti dalam penggunaan laman media sosial adalah penting bagi penjanaan pendapatan 
sampingan selebriti di Malaysia.

\section{Rujukan}

Angulo, N. (2016). 10 digital marketing trends to watch in 2016 and beyond. Marketing Dive. Retrieved from:http://www.marketingdive.com/news/10-digital-marketing-trends-to-watch-in-2016 andbeyond/411457/

Alice E. M. (2013). Status Update-Celebrity, Publicity, And Branding In The Social Media Age. Yale University Press. Haven \& London.

Appel, G., Grewal, L., Hadi, R., \& Stephen, A. T. (2019). The future of social media in marketing. Journal of the Academy of Marketing Science, 48(1), 79-95. https://doi.org/10.1007/s11747-01900695-1

Borison, R. (2014, September 10). Taylor Swift is incredibly good at being a celebrity. Retrieved from: http://www.businessinsider.com/

Brockington D., \& Henson S. (2015). Signifying the public: Celebrity advocacy and post-democratic politics. International Journal of Cultural Studies, 18(4), 431-448.

Chaffey, D., (2017). Global Social Media Statistics Summary 2017. Smart Insights. Retrieved from: http://www.smartinsights.com/social-media-marketing/social-media-strategy/new-globalsocial-mediaresearch/

Chang, Y., Li, Y., Yan, J., \& Kumar, V. (2019). Getting more likes: The impact of narrative person and brand image on customer-brand interactions. Journal of the Academy of Marketing Science, 1-19.

Christine M., \& Kowalczyk K. P. (2016). Transforming Celebrities through Social Media: The Role of Authenticity and Emotional Attachment. Journal of Product \& Brand Management, 25(4).

Clayton, T. (2013). 5 ways celebrities' social media presence evolved in 2012. Retrieved from: http://www.huffingtonpost.com/thomas-clayton/celebrities social media_b_2529151.html.

Colliander, J., \& Erlandsson, S. (2015). The blog and the bountiful: Exploring the effects of disguised product placement on blogs that are revealed by a third party. Journal of Marketing Communications, 21(2), 110-124.

Emma. N., \& Matilde P. (2017). Celebrities of Instagram - What Type of Content Influences Followers' Purchase Intentions and Engagement Rate? [non-published].

Fleck, N., Korchia, M., \& Le Roy, I. (2012). Celebrities in advertising: looking for congruence or likability?.Psychology \& Marketing, 29(9), 651-662.

Fraser, B., \& Brown, W. (2002). Media, celebrities, and social media influence: Identification with Elvis Presley. Spring, 5(2) 183-206. doi:10.1207/S15327825MCS0502_5

Freberg, K., Graham, K., McGaughey, K., \& Freberg, L. A. (2011). Who are the social media influencers? A study of public perceptions of personality. Public Relations Review, 37(1), 90-92.

Freire, O., Quevedo-Silva, F., Senise, D., \& Scrivano, P. (2018). The effectiveness of celebrity endorsement in aspiring new celebrities: Examining the effects of brand, congruence, charisma and overexposure. RAUSP Management Journal, 53(3), 289-303. https://doi.org/10.1108/RAUSP04-2018-011

Geser H. (2010). Tweeted thoughts and Twittered relationships: Some sociological remarks on the promise and limits of molecular online communications. Revista de Informatica Sociala, 13, 5-18. doi: dx.doi.org/10.5167/uzh-42416

Goh, K. Y., Heng, C. S., \& Lin, Z. (2013). Social media brand community and consumer behavior: Quantifying the relative impact of user-and marketer-generated content. Information Systems Research, 24(1), 88-107.

Gorin, V., \& Dubied. A. (2011). Desirable people: Identifying social values through celebrity news. Media, Culture \& Society, 33(4), 599-618.

Heine, C. (2016). Selena Gomez’s Social Media Posts Are Evidently Worth \$550,000 Apiece

Women rule Facebook, Twitter and Instagram. Adweek. Retrieved from:

http://www.adweek.com/digital/selena-gomezs-social-media-posts-are-evidently-worth-550000apiece172552/ 
Jin, S.A., \& Phua, J. (2014). Following celebrities' Tweets about brands: The impact of Twitter-based electronic word-of-mouth on consumers' source credibility perception, buying intentions, and social identification with celebrities. Journal of Advertising, 43, 181- 195.

Kapitan, S., \& Silvera, D. H. (2016). From digital media influencers to celebrity endorsers: attributions drive endorser effectiveness. Marketing Letters, 27(3), 553-567.

Kowalczyk, C.M., \& Pounders, K.R. (2016). Transforming celebrities through social media: the role of authenticity and emotional attachment. Journal of Product \& Brand Management, 25(4), 345-356. https://doi.org/10.1108/JPBM-09-2015-0969

Kozinets, R. V., De Valck, K., Wojnicki, A. C., \& Wilner, S. J. (2010). Networked narratives: Understanding word-of-mouth marketing in online communities. Journal of marketing, 74(2), 7189.

Linaschke J. (2011). Getting the Most from Instagram. Peachpit Press. ISBN: 0132875772 http://PhotoJoseph.com.

Mander, J. (2016). Social summary: GlobalWebIndex's quarterly report on the latest trends in social networking. Trendstream. Retrieved from: http://insight.globalwebindex.net/social

Marwick, A. (2013). Status Update: Celebrity, Publicity, and Branding in the Social Media Age. Yale University Press: New Haven \& London.

Miller, F., \& Allen, C. (2012). How does celebrity meaning transfer? Investigating the process of meaning transfer with celebrity affiliates and mature brands. Journal of Consumer Psychology, 22(3), 443-452. doi: 10.1016/j.jcps.2011.11.001

Remanadhan, S. et al. (2013). Social media used by community-based organizations conducting health promotion: a content analysis. BMC Public Health, 13. doi:10.1186/1471-2458-13-1129

Saige, D. (Dec 22, 2020). Instagram for Business: Everything You Need to Know. Business News Daily. Retrieved from: https://www.businessnewsdaily.com/7662-instagram-business-guide.html

Saraco, F. (Dec 18, 2020). Inside the Instagram Algorithm for 2021: How It Works and Where to Shift Your Strategy. Retrieved from: https://www.shopify.com/blog/instagram-algorithm.

Schouten, A. P., Janssen, 1., \& Verspaget M. (2020). Celebrity vs. Influencer endorsements in advertising: the role of identification, credibility, and Product-Endorser fit. International Journal of Advertising, 39:2, 258-28. DOI: 10.1080/02650487.2019.1634898

Silva, A. L., Lopes, E. L., Freire, O. B. D. L., \& Silva, D. da. (2015). The Brand's Effect on the Evaluation of Advertising Endorsed by Celebrities: an Experimental Study. Brazilian Business Review, 12(4), 57-78. https://doi.org/10.15728/bbr.2015.12.4.3

Siti Aisya \& Aini Maznina (2019). Celebrity-Fan Engagement on Instagram and Its Influence on The Perception of Hijab Culture Among Muslim Women in Malaysia. Jurnal Komunikasi:Malaysian Journal of Communication, 35(1), 286-302. https://doi.org/10.17576/JKMJC-2019-3501-19

Statistica.com (2021). Retrieved from: https://www.statista.com/statistics/250172/social-network-usageof-us-teens-and-young-adults/.

Tankovska H., (January 27, 2020). Distribution of Instagram users in the United States as of November 2020, by age group. Statista, Jan. 27, 2021. Retrieved from: https://www.statista.com/statistics/398166/us-instagram-user-age-distribution.

Turner, G., Studies, C., \& Turner, G. (2010). Approaching celebrity studies. Celebrity Studies, 1(1), 1120. http://doi.org/10.1080/19392390903519024

Vara, V., (2013). The celebrity as product. Retrieved from: http://www.newyorker.com/business/currency/the-celebrity-as-product

Ward, J. (2016). A Content Analysis of Celebrity Instagram Posts and Parasocial Interaction. Elon Journal of Undergraduate Research in Communications. Retrieved from: http://www.inquiriesjournal.com/a?id=1478

Wróblewski, L., \& Grzesiak, M., (2020). The Impact of Social Media on the Brand Capital of Famous People. Sustainability, 12(16), 1-17.

Yogesh K., Dwivedi, Elvira Ismagilova, D., Laurie Hughes, Jamie Carlson, Raffaele Filieri, Jenna Jacobson, Varsha Jain, Heikki Karjaluoto, Hajer Kefi, Anjala S., Krishen, Vikram Kumar, Mohammad M., Rahman, Ramakrishnan Raman, Philipp A,. Rauschnabel, Jennifer Rowley, Jari Salo, Gina A., Tran, Yichuan Wang, (2021). Setting the future of digital and social media marketing research: Perspectives and research propositions. International Journal of Information Management, Volume 59, ISSN 0268-4012. https://doi.org/10.1016/j.ijinfomgt.2020.102168. (https://www.sciencedirect.com/science/article/pii/S0268401220308082) 
Malaysian Journal of Social Sciences and Humanities (MJSSH), Volume 6, Issue 11, (page 51 - 65), 2021

DOI: https://doi.org/10.47405/mjssh.v6i11.1120

Zhang, J. Q., Craciun, G., \& Shin, D., (2010). When does electronic word-of-mouth matter? A study of consumer product reviews. Journal of Business Research, 63(12), 1336-1341. 